\title{
The practical implementation of enterprise balanced scorecard analysis system
}

\author{
G.A. Pollack ${ }^{1, *}$, and O.V. Ufimtseva ${ }^{1}$ \\ ${ }^{1}$ South Ural State University, Chelyabinsk, Russia
}

\begin{abstract}
The use of balanced scorecard system requires to use some measurable key performance indicators in every part of an enterprise activity, not only for the enterprise itself and its subdivisions, but for every employee. These actions need the introduction/application of a corporate information system. In this work we suggest the most commonly used Russian software "1C: Enterprise Platform" (Accounting system of enterprise). We present the practical implementation of the system of real-time monitoring, analysis and control for the implementation of actions concerned with financial component of the enterprise-balanced scorecard. The formed module (expansion) can be applied in pattern "1C: ERP" (Enterprise Recourse Planning). The conclusion is made about the possibility of the above information system expansion for the implementation of all components of the enterprise balanced scorecard system.
\end{abstract}

\section{Introduction}

Modern conception of an enterprise strategic management directs production activity toward customer's needs responds flexibly and makes timely changes in reply to outer challenge. The goal of proper management is to gain competitive preference that can give the enterprise an opportunity to survive in long-term outlook $[4,5,8,12,16]$.

During the development of administrative resolutions it is advisable to use the system of key indicators which are:

- very important for the rating of company operation;

- estimated in a quantitative sense;

- measured and tracked easily.

Modern technology of strategic management is based on the conception of balanced scorecard (BSC) [1, 2, 9], that gives a company a chance not only to work out an advantageous strategy, but to implement it successfully. The balanced scorecard takes into account not only financial but non-financial indicators which show four important parts of the enterprise activity:

- financial;

- customer relationship;

- inner business-processes;

- staff situation and development of interior infrastructure.

"It is impossible to manage something that can't be measured". One of the main ideas in the basis of balanced scorecard is the idea of measurability. All the factors that are important for the management of the enterprise should be measured and presented in the form of interconnected and balanced key performance indicators - KPI [5].
All the factors that are important for the management of the enterprise should be measured and presented in the form of interconnected and balanced key performance indicators [3].

Performance indicators can be fixed both for the enterprise itself and for each subdivision and employee.

\section{Implementation of balanced scorecard analysis system}

To use efficiently the system of balanced scorecard at the enterprise, it is necessary to work out and introduce the information system, which can ensure fixation and analysis of key performance indicators for both each employee and the whole enterprise $[1,2,13,15,16]$.

For most enterprises, financial direction provides the interrelation of all four components of scorecard system $[7,8,17]$. The following goals can be stated for a financial component:

- expenses cut;

- rise in receipts;

- rise in cash;

- profit increase.

The following indicators are necessary to estimate the attainability of every goal.

Goal 1: Expenses cut.

Indicator: share of expenses in receipts.

The indicator is calculated as the ratio of all expenses to receipt volume.

Goal 2: Receipt increase.

Indicators: Receipt amount in value terms (absolute indicator), increase of receipts, $\%$. 
Rise in receipts, $\%=(($ receipts in reporting period receipts in prior period $) \times 100 \% /$ receipts in reporting period.

Goal 3: Rise in cash.

Indicators: Cash in basic activity, free cash.

Goal 4: Profit increase.

Indicators: Gross profit, acceleration of gross profit, $\%$

Acceleration of gross profit, $\%=($ Gross profit in reporting period - gross profit in prior period) $\times 100 \%$.

Goal 5: Return on total assets (ROTA).

Indicator: Indicator of total assets profitability

$$
\text { ROTA }=\text { EBIT } / \text { Total net assets. }
$$

In order to attain these goals special measures can be developed. As to a financial component, these are the following measures:

1. Introduction of Budget System for the goal "Rise in cash".

2. Advertising for the goal "Rise in receipts".

3. Formation / use of exterior capital for the goal "Rise in receipts".

4. Outlet expansion for the goal "Profit increase".

5. Range expansion for the goal "Profit increase".

6. Decline in value of additional expenditure for the goal "Expenses decline".

Each measure is characterized by its value and effectiveness of its effect on the goal.

The most popular for working out business resolutions at Russian enterprises are "1C:Enterprise 8.3" [10, 11]. We are going to show based on 1C Platform how to implement the information system for the analysis in realtime efficiency indicators of financial component.

For valuable analysis of balanced indicator system it is necessary to have the possibility of storing in database the information about the goals of enterprise strategic development, the key indicators of succeeding, the measures to be taken, etc. Moreover, in order to plan the strategy and analysis of enterprise development it is necessary to store the history of indicators, to compare assembled information using reports and diagrams.

It required introducing into the pattern some additional catalogs and registers as well as necessary reporting.

The following information is referred to supplemental:

- The enterprise strategic development goals ("Strategic goals" catalog).

- The goals of succeeding ("Indicators" catalog).

- Measures taken to attain strategic goals ("Strategic measures" catalog).

For example, the catalog "Strategic goals" has the following structure (Fig. 1).

Every goal has a list of indicators that influence on its implementation. As some indicators influence on the attainment rate unequally - the characteristic "Indicator significance» is introduced to the table "Indicators". This characteristic takes into account the rate of the above indicator influence on succeeding.

The attribute "Goal value" is some previously calculated amount (planned value). Its actual attainment indicates total goal attainment. The goal actual amount is also used; it is a design quantity and is presented in reports.

It is a sum of indicator significance products multiplied by indicator actual value and divided by indicator planned value:

$$
\begin{aligned}
\text { Goal_value }= & \sum_{i=1}^{n} \frac{\text { actual_value }_{i}}{\text { planned_value }_{i}} \times \\
& \times \text { indicator_significance }_{i}
\end{aligned}
$$

To control the implementation rate of the assigned goal, we use the allowable variation of the assigned goal from the plane value. The history of planned and actual indicator values is stored in the information register (Fig.2).

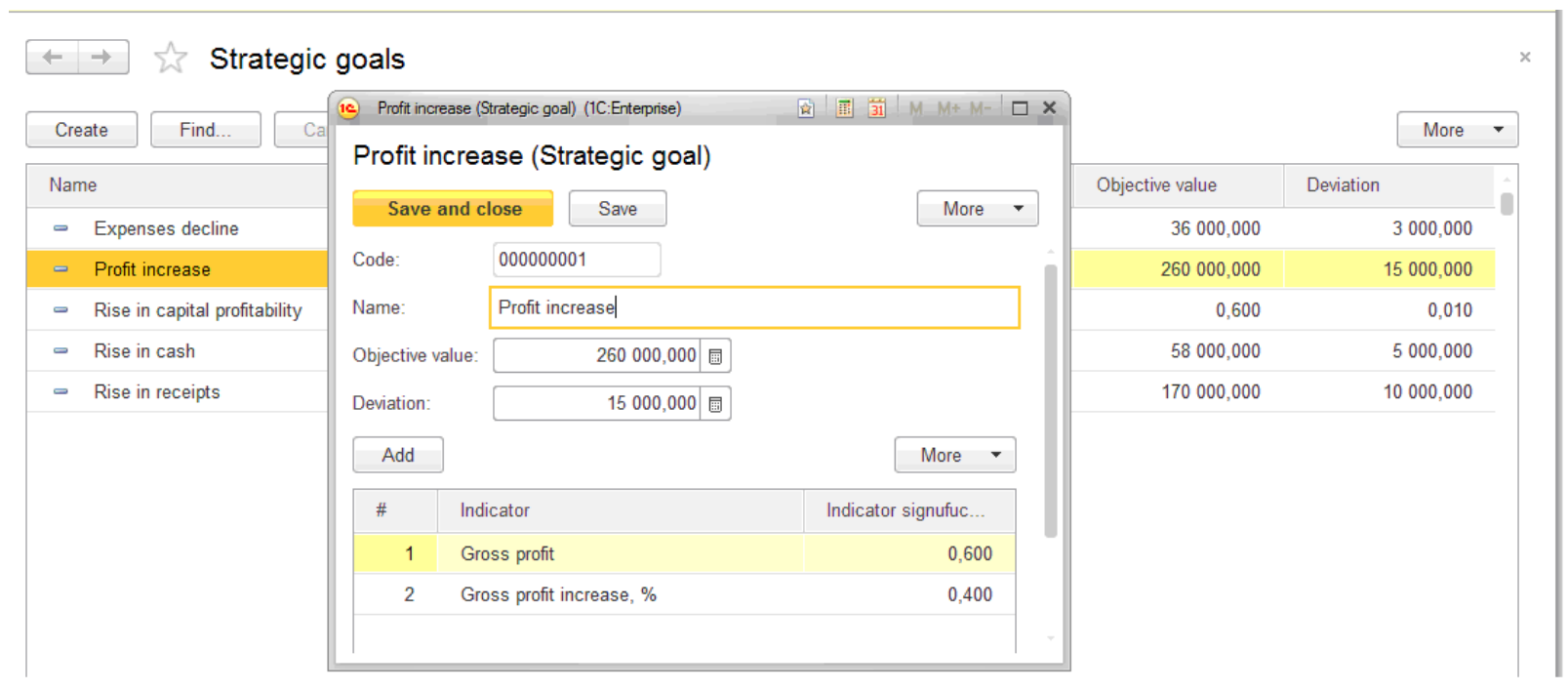

Fig. 1. Structure of catalog "Strategic goals". 


\section{History of indicator change}

\begin{tabular}{|c|c|c|c|c|c|c|}
\hline \multicolumn{2}{|c|}{ Create } & Cancel search & & & \multicolumn{2}{|c|}{ More $>$} \\
\hline Peri & $\downarrow$ & Indicator & Planned value & Actual value & & \\
\hline$\infty$ & 01.03 .2016 & Cash in principal activity & 58000,000 & & 60000,000 & \\
\hline 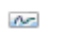 & 01.05 .2016 & Gross profit & 250000,000 & & 230000,000 & \\
\hline$\infty$ & 01.05 .2016 & Capital profitability indicator & 0,600 & & 0,660 & \\
\hline$\omega$ & 01.05 .2016 & Currency of balance & 360000,000 & & 350000,000 & \\
\hline$\infty$ & 01.06 .2016 & Receipts volume in value terms & 170000,000 & & 150000,000 & \\
\hline$\infty$ & 01.06 .2016 & Rise in receipts, $\%$ & 23,000 & & 26,000 & \\
\hline$\infty$ & 01.06 .2016 & Spare cash & 35000,000 & & 38000,000 & \\
\hline$\infty$ & 01.06 .2016 & Share of expenses in sales volume & 36000,000 & & 30000,000 & \\
\hline
\end{tabular}

Fig. 2. Register structure "History of indicator changes".

The following reports are suggested to be used for getting some analytical information containing resulting aggregated or detailed information, which is formed according to certain standards.

1. Report "BSC-monitoring in terms of key performance indicators" is a monthly general report where all indicators are presented in the light of the enterprise strategic goals (Fig.3).

2. "BSC-monitoring in terms of implementation goals" report in terms of performance goals is a monthly general report where all the indicators are presented in terms of strategic goals of the enterprise as well as their planned and actual value, indicator significance and color indicator of attainment. The color indicator is green when the planned value has been attained, it is yellow when the value has not changed, it is red when the indicator value has gone down (Fig.4).

3. In the report "The attainment rate of strategic goals", the information about the enterprise goals values is presented. It is necessary for a manager to analyze the information. The results of the report analysis will allow paying attention to some neglect at the enterprise.

4. In the report "The effectiveness of measure influence on the indicator improvement", the list of the above measures is presented. For each measure are presented the following: date of commencement and expiry date, cost and rate of influence on certain indicators. The list of measures can be reviewed over any period.

We used "1C:Enterprise Platform" (Accounting system of enterprise) to implement the analysis information system for the financial component of balanced scorecard. The above module can be introduced in "1C:ERP" (Enterprise Recourse Planning).

The system can be completed with some modules which will analyze indicators which characterize customer relations, interior business-processes, staff situation and development of the enterprise interior infrastructure.

Taking into account that today a lot of Russian enterprises use this software, further work in this direction looks perspective.

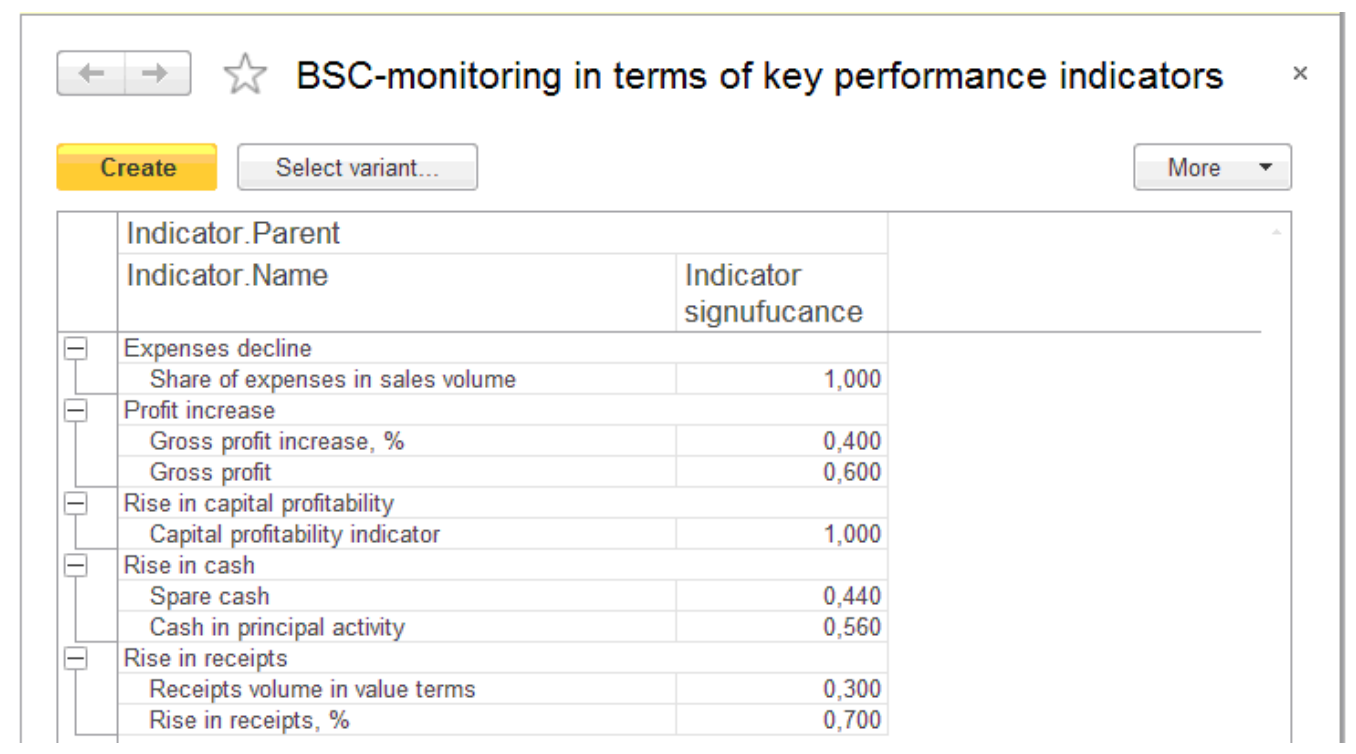

Fig. 3. Report BSC-monitoring in terms of key performance indicators. 


\begin{tabular}{|c|c|c|c|c|c|c|}
\hline & $\rightarrow$ & BSC-mor & terms of imp & lementation & \multicolumn{2}{|l|}{ la } \\
\hline \multicolumn{2}{|c|}{ Create } & Select variant... & & & More & 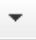 \\
\hline \multicolumn{3}{|c|}{ Indicator.Name } & Planned value & Actual value & & \\
\hline \multicolumn{3}{|c|}{ Gross profit } & 250000,000 & 230000,000 & & \\
\hline \multicolumn{3}{|c|}{ Cash in principal activity } & 58000,000 & 60000,000 & & \\
\hline \multicolumn{3}{|c|}{ Currency of balance } & 360000,000 & 350000,000 & & \\
\hline \multicolumn{3}{|c|}{ Capital profitability indicator } & 0,600 & 0,660 & & \\
\hline \multicolumn{3}{|c|}{ Rise in receipts, $\%$} & 23,000 & 26,000 & & \\
\hline \multicolumn{3}{|c|}{ Share of expenses in sales volume } & 36000,000 & 30000,000 & & \\
\hline \multicolumn{3}{|c|}{ Receipts volume in value terms } & 170000,000 & 150000,000 & & \\
\hline \multicolumn{3}{|c|}{ Spare cash } & 35000,000 & 38000,000 & & \\
\hline
\end{tabular}

Fig. 4. Report BSC-monitoring in terms of implementation goals.

\section{Conclusion}

The system of the analysis of financial factors has a modular approach that makes it possible to introduce it in the present corporate information system of the enterprise based on "1C:Enterprise Platform" (Accounting system of enterprise). It allows solving the following tasks:

1. To control real-time the attainment of indicator's efficiency both for every employee and for every subdivision and the whole enterprise as well.

2. To analyze detailed and resulting information in terms of assigned goals.

3. To analyze the enterprise key performance indicators (KPI) and estimate them in the view of the attainment of the enterprise strategic goals.

4. To make operative decisions and correct the system of measures those are directed to the attainment of the enterprise strategic goals.

The corporate information system based on "1C:Enterprise Platform" can be completed with modules that will analyze the indicators which characterize the customer relation, interior business processes, staff situation and the development the enterprise interior infrastructure.

So, based on one decision it is possible to implement in practice the analysis of all the components of the balanced scorecard. Taking into account that today a lot of Russian enterprises use this software, further work in this direction looks perspective.

The work was supported by Act 211 Government of the Russian Federation, contract № 02.A03.21.0011.

\section{References}

1. R.S. Kaplan, D.P. Norton, The balanced scorecard: translating strategy into action (Olimp-Biznes, Moscow, 2006)

2. R.S. Kaplan, S.R. Anderson, Time-Driven ActivityBased Costing: a simpler and more power-ful path to higher profits (Harvard Business School Publishing Corporation, Boston, 2007)

3. M. Gavrikov, Corporate Financial Management, 01(13), 37 (2006)

4. V.G. Kandalintsev, Innovation business: use of balanced scorecard (Delo ANH, Moscow, 2010)
5. V.G. Kandalintsev, Balanced management of enterprise (Knorus, Moscow, 2006)

6. S.I. Krylov, 21(420), 2-14 (2015)

7. T.V. Logvinova, Financial management, 1, 20-24 (2007)

8. L. Mullagildina, in Proc. Information technologies in science, management, social sphere and medicine, 273$276(2015)$

9. O. Nils-Göran, J. Roy, M. Wetter, Performance Drivers. A Practical Guide to Using the Balanced Scorecard (Vil'yams, Moscow, 2006)

10. M.G. Radchenko, E.Yu. Khrustaleva, 1C:Enterpise 8.2. Developer's practical manual. Examples and standard techniques (1C-Pablishing, Moscow, 2009)

11. O.A. Romanenko, Economics and enterprise, 113(523), $772-776$ (2014)

12. N.O. Rukhlyada, Theoretical and applied aspects of modern science, 137-142 (2015)

13. R. Rumelt, Good Strategy. Bad Strategy. The difference and Why it Matters (London, 2012)

14. N.A. Ryazantseva, D.N. Ryazantsev, 1C:Enterprise 8.0. Management of manufacturing enterprise (BHVPeterburg, St. Petersburg, 2006)

15. P. Khorvart, Theoretical and Practical Aspects of Management, 4, 13-22 (2000)

16. Horvath \& Partners, Balanced Scorecard umsetzen (Al'pina Pablisher, Moscow, 2008)

17. P. KHorvart, Theoretical and Practical Aspects of Management, 13-22 (2000)

18. A.A. Tsupko, A Series Economy, Finance and Production Management, 2, 61-66 (2011)

19. V.A. Shchelkova, S.G. Shchelkova, Proc. of the III International Scientific Conference, 223-225 (2014)

20. P.R. Niven, Balanced Scorecard Step-by-Step: Maximizing Performance and Maintaining Results (Hoboken, 2006)

21. V. Biryukov, Using the Balanced Scorecard in Controlling by the Example of the Polygraph Industry (Moscow, 2010)

22. L.R. Batukova, G.Y. Belyakova, Fundamental research, 2-21, 4705-4709 (2015)

23. A.V. Krasnikova, Ekonominfo, 23, 43-47 (2015) 